\title{
Urgences
}

\section{Pendant que deux clowns...}

\section{Vianney Gallant}

Numéro 10, 2e trimestre 1984

Spécial fantasmes

URI : https://id.erudit.org/iderudit/025159ar

DOI : https://doi.org/10.7202/025159ar

Aller au sommaire du numéro

Éditeur(s)

Urgences

ISSN

0226-9554 (imprimé)

1927-3924 (numérique)

Découvrir la revue

Citer ce document

Gallant, V. (1984). Pendant que deux clowns... Urgences, (10), 89-92.

https://doi.org/10.7202/025159ar

Ce document est protégé par la loi sur le droit d'auteur. L'utilisation des services d'Érudit (y compris la reproduction) est assujettie à sa politique d'utilisation que vous pouvez consulter en ligne.

https://apropos.erudit.org/fr/usagers/politique-dutilisation/
Cet article est diffusé et préservé par Érudit.

Érudit est un consortium interuniversitaire sans but lucratif composé de l’Université de Montréal, l'Université Laval et l'Université du Québec à Montréal. Il a pour mission la promotion et la valorisation de la recherche. https://www.erudit.org/fr/ 


\section{VIANNEY GALLANT}


Pendant que deux clowns en redingote froissaient dans leurs faux pas les chapeaux melon de l'habitude, après que les gorilles de la présentation eurent récité l'ordinaire, que les soubrettes d'une cacophonie à la mode, les jambes levées et dépouillées dans le style de la décennie, eurent circonscrit son rythme, de longs soupirs ondulés d'absence inondèrent la salle.

L'heure flottait sur la valse des dires. Le spectacle était désert. Comme des tracts lancés d'un ballon, des feuilles à partitions multiples glissaient dans l'air. L'un de ces confettis lignés fit son atterrissage sur mes genoux.

Les ombres du décor écrivaient dans mon dos. Je reconnus les passages qui m'étaient destinés. L'enchaînement des dialogues et des personnages était si flou, de genres si différents, que je me sentis cloué un moment à mon siège par une angoisse innommable. Les présences clignotaient tout autour.

Deux pierrots obèses quittèrent leurs sièges, déambulant dans l'allée centrale, tels des juges élus à cette fonction par un romantisme usé jusqu'à l'atrophie. Depuis leurs regards, la loi des errances sentimentales lançait ses questions. Ils avançaient d'un pas péremptoire, écrasant dans leur sillage le large amoncellement de confettis étalés comme un tapis. Les feuilles savantes laissaient entendre leurs cris de chiffons froissés. Deux mousquetaires séniles (I'héroïsme en dehors de l'écran ça fait vieux jeu) semblaient constituer leur arrièregarde, la main-réflexe éternellement mariée à l'épée du souvenir.

Je me contrains, trop tard peut-être, à me pénétrer du fouillis des scénettes rougies à l'encre transparente, pour m'apercevoir que nous étions au seuil du deuxième acte... À peine la turbulence roucoulante des applaudissements étouffée, je devais monter sur scène et graver dans mon rôle tout l'art de l'interprétation.

Vous croyez-vous donc en ce monde comme à une entrevue pour choisir des acteurs? 
"Mais où est donc le metteur en scène?" aurais-je dû crier. Au lieu de cela je contemplai mon désarroi dans le miroir de l'instant. D'ombre en ombre le spectacle déroulait ses mouvances élastiques et trop amovibles à mon goût. Je vivais I'hésitation douloureuse et inutile de celui qui, face à l'improbable total, n'a le choix que de faire le plongeon fatal... ayant à peine saisi le sens du mot...

Mal préparé, dans le seul appareil anachronique de ma bonne volonté, je me cherchai dans les dizaines de costumes abandonnés sur les sièges voisins. Géant ou nain, opaque ou opalescent, je n'entrai dans aucun. Pas plus dans Goliath que dans le Petit Poucet, ni dans Goldorak, ni dans le pharisien. Décidément, ça n'allait pas. Je m'emparai de la crosse d'or millénaire d'un évêque richissime et pervers et je m'apprêtai à tirer comme Daniel Boone sur tout ce qui bougeait... Dans leur nacelle Nic et Pic descendaient juste à l'avant du rideau où je mirais mes sacrilèges. J'eus peur d'interrompre leur goûter (oh tendresse...). Je ne fus pris que par la force du recul... Je me terrai un moment dans la tanière d'un silence antarctique et bioionique, encastré dans les tropiques grandiloquents d'une solitude luckylukienne, envahi par un grand oeil paranoïde et kafkaïen.

Face à l'imminence de ma commission, je résolus d'accomplir mon dernier acte avant le deuxième... Je bondis de mon siège, désireux d'interroger les actants qui tour à tour avaient quitté la salle pour s'agglutiner sur la scène puis s'engloutir dans les coulisses. Chacun d'eux avait plutôt l'air de s'engager dans I'anarchie d'un bal costumé. Je rencontrai une reine travestie dont la couronne plaquée or trahissait la précarité de son Verbe. Ma quête fut vaine. L'apparente dame était escortée par quatre robots de l'âge de pierre, anachronisme trépidant, et une demi-douzaine de fonctionnaires indécents formaient une longue traîne, issue de l'érotisme atavique des bureaux à néons. En un éclair, je réalisai tout l'absurde de la performance que j'avais à accomplir. II ne restait dans la salle qu'une vieille ombre masquée et la lumière qui l'engendrait ne me semblait venir de nulle part. L'objet dont elle était le reflet me demeurait inconnu lui aussi. 
Je me tins debout sur la scène. Un flot de tâches rouges dansant dans ma tête, titubant, sans doute sous les projecteurs de la mémoire, les yeux fixés sur l'oasis-mirage du règne et de la durée, les pieds gonflés par la couleur brûlante du plus trouble des désirs. Je braquai mes phrases en direction de l'ombre aperçue dans le recoin de mes angoisses, m'obligeant ainsi à bien rendre ces caillots tachés de sens.

Je débitai comme une usine un bois indifférencié, les brans de syllabes lactant ma gorge en entonnoir phonétique, un texte araignée plein de vagues et de marées, avec des souffles de drame sur la comédie et des rires gaulois dans les passages sensibles, imaginant et composant des pauses précipices, dans des univers sans virgules, au relief de mauvais rêve.

Le mensonge théâtral déployait ses voiles, tandis que je défaillais encore à la barre d'une possible abstention. Au beau milieu du centre nerveux de la conscience, le fantôme de l'opéra remplissait à mesure mes trous de mémoire, en se balançant d'un lustre à l'autre dans les couloirs vertigineux des paragraphes sans répliques.

Des serpents de vocalises électroniques, greffés au filage des microphones, me ligotaient au pied du mur... Un! Deux! Trois! Le rideau tomba. Ouf! C'était l'entracte. Laissé pour mort, je pus me glisser furtivement hors des noeuds désormais inertes des mirages du signifiant, et je réussis à me faufiler jusqu'à la sortie de secours. Au fond de I'antimémoire, des ombres s'enlisaient.

Dans la crainte de l'effet Pinocchio, je préférai sombrer dans l'oubli... du réveil. 